\title{
Genomic Fingerprinting by Arbitrarily Primed Polymerase Chain Reaction Resolves Borrelia burgdorferi into Three Distinct Phyletic Groups
}

\author{
JOHN WELSH, ${ }^{1 *}$ CHARLES PRETZMAN, ${ }^{2}$ DANIELLE POSTIC, ${ }^{3}$ ISABELLE SAINT GIRONS,${ }^{3}$ \\ GUY BARANTON, ${ }^{3}$ AND MICHAEL MCCLELLAND ${ }^{1}$
}

Califormia Institute of Biological Research, 11099 North Torrey Pines Road, La Jolla, California 92037'; Vector Borne Disease Unit, Ohio Department of Health, Columbus, Ohio 43201 ${ }^{2}$; and Unite de Bacteriologie Moleculaire et Medicale, Institut Pasteur, 75724 Paris Cedex 15, France ${ }^{3}$

\begin{abstract}
The causative agent of Lyme disease, Borrelia burgdorferi, was first identified by Burgdorfer et al. in 1982 (W. Burgdorfer, A. G. Barbour, S. F. Hayes, J. L. Benach, E. Grunwaldt, and J. P. Davis, Science 216:1317-1319, 1982) and was isolated by Barbour et al. in 1983 (A. G. Barbour, W. Burgdorfer, S. E. Hayes, O. Peter, and A. Aeschlimann, Curr. Microbiol. 8:123-126, 1983). Since then, a large number of isolates have been collected, and there have been questions regarding the relationships among the various strains. Using genomic fingerprinting by an arbitrarily primed polymerase chain reaction, we resolved into three groups a collection of Eurasian and North American isolates of spirochetes that are generally categorized as $B$. burgdorferi. Group I strains have been identified in both North America and Eurasia, while strains belonging to Borrelia groups II and III have been found only in Eurasia. These same three groups have also been delineated by Baranton et al. (G. Baranton, D. Postic, I. Saint Girons, P. Boerlin, J.-C. Piffaretti, M. Assous, and P. A. D. Grimont, Int. J. Syst. Bacteriol. 42:370-375, 1992) by independent methods. Two isolates are distinct from all of the other strains in our collection but are clearly members of the genus Borrelia.
\end{abstract}

In the United States, Lyme disease is the most common vector-borne disease, with approximately 6,000 new cases reported each year. This disease was not recognized as a distinct clinical entity in the United States until 1970 (22), although a similar disease had been known in Europe since 1910 (2). In 1977, Steere and colleagues (24) described the complex of symptoms that were associated with an unusual cluster of childhood arthritis in Lyme, Conn. Among these symptoms was erythema chronicum migrans, the symptom that was originally reported by Afzelius in 1910. In 1982, the spirochetal agent of Lyme disease was isolated (7), and it was eventually proved that the disorder is caused by this spirochete, Borrelia burgdorferi (15).

Sixty years elapsed between the original description of erythema chronicum migrans in Europe and the description of Lyme disease symptoms in North America. Several factors may be important in the human epidemiology of Lyme disease, including the population expansion of the tick vector and large reservoirs of infected hosts, including white-tailed deer and white-footed mice $(3,7)$. A retrospective study in which the polymerase chain reaction (PCR) was used showed that $B$. burgdorferi was present in North America as early as 1940 (18). The observations that plasmid profiles vary in different isolates of the spirochete (6) and that the loss of virulence upon repeated passage correlates with the loss of plasmids (21) raise the possibility that some genetic elements may be horizontally mobile. We began a study of the ecology of $B$. burgdorferi by determining the distribution of genotypes in North America and Europe.

Several investigators have suggested distinctions between $B$. burgdorferi isolates on the basis of results obtained with phenotypic and genotypic taxonomic methods. The results of the experiments that have been performed generally support the idea that $B$. bungdorferi strains are actually

\footnotetext{
* Corresponding author.
}

members of more than a single species, but the distinctions among species or subspecies that are generally subsumed under the name $B$. burgdorferi have not been fully elaborated. The methods used have involved comparisons of major proteins $(8)$, antigenic behavior $(9,32)$, restriction fragment profiles (17), plasmid profiles $(6,23,25)$, PCR results (20), DNA-DNA hybridization results (19), and DNA sequencing results (1). The general finding has been that isolates from North America and Europe tend to be more similar to other isolates from the same continent than to isolates from the other continent (17). In this study we used a new PCR-based method to address this question.

The standard PCR consists of repeated cycles of template denaturation, primer annealing, and primer extension. By reducing the stringency of the primer annealing step, a single primer that has no known homology to a genome can anneal at sites for which the match is imperfect. When two such adequate but imperfect annealing sites occur within several hundred bases of each other and in the proper orientation, the sequence between the sites can be amplified. Subsequent cycles with high-stringency annealing steps allow only those first successful products to amplify. The products are resolved by electrophoresis and yield reproducible, arbitrarily primed PCR (AP-PCR) fingerprints, with the differences between fingerprints reflecting differences in the sequences of the templates. This method has been used previously to compare intra- and interspecific differences in bacteria (29) and for genetic mapping in eukaryotes $(28,30,31)$.

We used AP-PCR fingerprinting to divide a collection of 14 European, 13 North American, and 2 Japanese isolates into genospecific groups. Three of the groups, groups I, II, and III, correspond to $B$. burgdorferi sensu stricto, Borrelia garinii, and group VS461, respectively, as described in the accompanying paper by Baranton et al. (5). Two other isolates included in this study are related to, but somewhat different from, these three phyletic groups. The classification of these isolates will require further study. 
TABLE 1. Strains used in this study

\begin{tabular}{|c|c|c|}
\hline Strain & Origin & $\begin{array}{l}\text { Geographic } \\
\text { location }\end{array}$ \\
\hline \multicolumn{3}{|l|}{ Group I strains } \\
\hline IP2 & Human $(\mathrm{CSF})^{a}$ & France \\
\hline 212 & Lxodes ricinus & France \\
\hline B31 (= ATCC 35210) & Lxodes dammini & United States \\
\hline 27985 & Lxodes dammini & United States \\
\hline HUM3336 & Ixodes pacificus & United States \\
\hline HUM7814 & Ixodes pacificus & United States \\
\hline SON328 & Lxodes pacificus & United States \\
\hline SON188 & Ixodes pacificus & United States \\
\hline LAKE339 & Ixodes pacificus & United States \\
\hline CA5 & Ixodes pacificus & United States \\
\hline CA6 & Ixodes pacificus & United States \\
\hline 19535 & Peromyscus leucopus & United States \\
\hline 21305 & Peromyscus leucopus & United States \\
\hline 21343 & Peromyscus leucopus & United States \\
\hline 26816 & Microtus pennsylvanicus & United States \\
\hline \multicolumn{3}{|l|}{ Group II strains } \\
\hline 20047 & Lxodes ricinus & France \\
\hline G25 & Lxodes ricinus & Sweden \\
\hline N34 & Lxodes ricinus & Germany \\
\hline TN & Lxodes ricinus & Germany \\
\hline T25 & Lxodes ricinus & Germany \\
\hline VS286 & Lxodes ricinus & Switzerland \\
\hline VS468 & Lxodes ricinus & Switzerland \\
\hline PBi & Human (CSF) & Germany \\
\hline $\mathbf{P B r}$ & Human (CSF) & Germany \\
\hline HP3 & Ixodes persulcatus & Japan \\
\hline \multicolumn{3}{|l|}{ Group III strains } \\
\hline $\mathrm{BO} 23$ & Human (CSF) & Germany \\
\hline PGau & Human (CSF) & Germany \\
\hline VS461 & Lxodes ricinus & Sweden \\
\hline \multicolumn{3}{|l|}{ Unclassified strains } \\
\hline DN127 & Ixodes pacificus & United States \\
\hline HO14 & Lxodes ovatus & Japan \\
\hline
\end{tabular}

${ }^{a} \mathrm{CSF}$, cerebrospinal fluid.

\section{MATERIALS AND METHODS}

Preparation of DNA. The strains used in this study are listed in Table 1. All of the isolates were grown in BSKII medium (7) in 1-liter flasks containing 800 or $900 \mathrm{ml}$ of medium. The flasks were incubated at $34^{\circ} \mathrm{C}$ for 6 to 12 days until the density was $2 \times 10^{8}$ to $4 \times 10^{8}$ cells per ml. Cells were harvested by centrifugation at $10,000 \times g$ for $30 \mathrm{~min}$ during the late logarithmic phase of growth and were washed in phosphate-buffered saline $\left(8 \mathrm{mM} \mathrm{Na} \mathrm{HPO}_{2}, 1.5 \mathrm{mM}\right.$ $\mathrm{KH}_{2} \mathrm{PO}_{4}, 0.02 \% \mathrm{KCl}, 0.8 \% \mathrm{NaCl} ; \mathrm{pH} \mathrm{7.2)}$. The bacteria were lysed and the DNA was extracted and purified as described by Brenner et al. (11). The following primers were purchased from Genosys (Houston, Tex.): KpnR (5'CAAGTCGACATGGCACRTGTATACATAYGTAAC- $3^{\prime}$ ), sequencing primer (5'-TTGTAAAACGACGGCCAG-3'), and reverse sequencing primer (5'-GGAAACAGCTATG ACCATGA-3').

AP-PCR fingerprinting. Fingerprinting was performed as described previously (28). Reaction mixtures $(10 \mu \mathrm{l})$ contained 50,10, and sometimes $2.5 \mathrm{ng}$ of DNA, 1× Taq polymerase buffer, $4 \mathrm{mM} \mathrm{MgCl}{ }_{2}$, deoxynucleoside triphosphates at concentrations of $0.2 \mathrm{mM}$ each, $10 \mu \mathrm{M}$ oligonucleotide primer, and $0.025 \mathrm{U}$ of Taq polymerase (Perkin ElmerCetus, Norwalk, Conn.). These reaction mixtures were subjected twice to the following low-stringency temperature profile cycle: $94^{\circ} \mathrm{C}$ for $5 \mathrm{~min}$ to denature the DNA, $40^{\circ} \mathrm{C}$ for $5 \mathrm{~min}$ for low-stringency annealing, and $72^{\circ} \mathrm{C}$ for $5 \mathrm{~min}$ for extension. These cycles were followed by 10 high-stringency temperature profile cycles $\left(94^{\circ} \mathrm{C}\right.$ for $1 \mathrm{~min}$ to denature the compounds, $60^{\circ} \mathrm{C}$ for $1 \mathrm{~min}$ for high-stringency annealing, and $72^{\circ} \mathrm{C}$ for $2 \mathrm{~min}$ for extension). A $40-\mu$ l portion of a labeling mixture consisting of $1 \times$ Taq polymerase buffer, 4 $\mathrm{mM} \mathrm{MgCl}{ }_{2}$, deoxynucleoside triphosphates at concentrations of $0.2 \mathrm{mM}, 1 \mathrm{U}$ of Taq polymerase (Perkin ElmerCetus), and $5 \mu \mathrm{Ci}$ of $\left[\alpha{ }^{32} \mathrm{P}\right] \mathrm{dCTP}$ was added, and the preparation was subjected to 30 additional high-stringency temperature profile cycles. Thermocycling was performed with a model 9600 DNA thermocycler (Perkin Elmer). The two-step process was used so that the primer concentration could be kept high during the early rounds. A simpler one-step process has now been published (29a) that is equally effective. An AP-PCR with two or three template concentrations is strongly advised. This reduces the possibility of misscoring polymorphisms that are caused by inadequacies in technique or materials.

Electrophoresis. Fingerprints were resolved on 5\% acrylamide-50\% urea sequencing gels run in a Poker Face SE 1500 sequencer apparatus obtained from Hoefer Scientific Instruments, San Francisco, Calif. Electrophoresis at 1,500 $\mathrm{V}$ was continued until the xylene cyanol tracking dye was approximately $10 \mathrm{~cm}$ from the bottom. The gels were exposed to Kodak X-Omat X-ray film.

Phylogenetic analysis. To analyze the fingerprint data, we used two phylogenetic inference packages, PAUP (phylogenetic analysis using parsimony) (26) and PHYLIP (phylogeny inference package) (13). The fingerprint data were collected and analyzed in blind experiments. Phylogenetic analysis in bacteria has been reviewed by Woese (33).

\section{RESULTS}

Genomic fingerprinting by AP-PCR. Genomic fingerprints were generated by using AP-PCR (28). Examples of the fingerprints obtained for the collection of $B$. burgdorferi sensu lato strains listed in Table 1 are shown in Fig. 1. Each band on the gel was scored as 1 (present) or 0 (absent). Faint products in exposures were scored by using longer exposures. The presence or absence of a band was presumably determined by either a polymorphism in the length of the sequence lying between two successful priming sites, much the same as with restriction fragments, or a sequence polymorphism underlying the low-stringency priming site. The scores for three experiments (one experiment performed with each of the three primers [KpnR, reverse sequencing primer, and sequencing primer]) yielded the data matrix shown in Fig. 2. Using three primers with 27 isolates, we scored 54 polymorphic characters, 34 of which were shared by two or more taxa. Isolates VS468, VS286, and PBi were identical in this analysis, so only one of these three, strain $\mathrm{PBi}$, was included in the data matrix. Strains CA5 and CA6 were also identical, and only strain CA5 was included in the data matrix. The characters we scored could be used to estimate genetic distances or could be used, with qualification, in a parsimony analysis. Scoring AP-PCR polymorphisms as simple binary characters is an approximation. As is the case with restriction fragment polymorphisms, the probabilities of losing and regaining a band are unknown and are not expected to be equal, thereby complicating phylogenetic analysis when parsimony is used. Also, length polymorphisms are usually indistinguishable from true presence or absence polymorphisms, so that some of the characters are not truly independent. With these difficulties in mind, we demonstrated that the phylogenetic trees built by using 


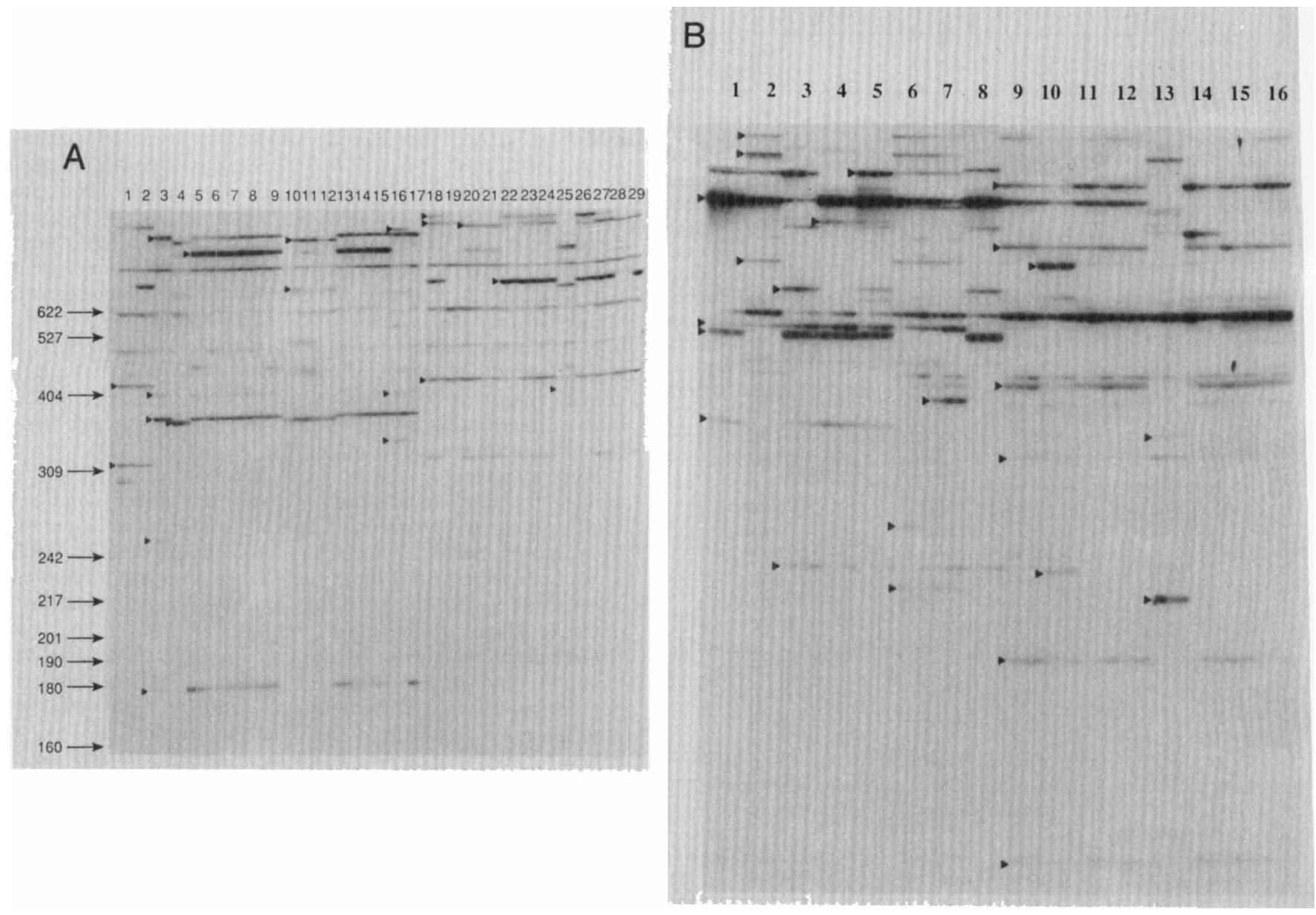

FIG. 1. AP-PCR fingerprints of Borrelia strains listed in Table 1. (A) Reverse sequencing primer. Lane 1, strain 212; lane 2, strain IP2; lane 3, strain 20047; lane 4, strain VS461; lane 5, strain VS286; lane 6, strain VS468; lane 7, strain N34; lane 8, strain PBi; lane 9, strain PBr; lane 10, strain PGau; lane 11, strain BO23; lane 12, strain PGau; lane 13, strain T25; lane 14, strain TN; lane 15, strain G25; lane 16, strain HO14; lane 17, strain HP3; lane 18, strain HUM3336; lane 19, strain HUM7814; lane 20, strain LAKE339; lane 21, strain SON188; lane 22, strain SON328; lane 23, strain CA5; lane 24, strain CA6; lane 25, strain DN127; lane 26, strain 21305; lane 27, strain 27985; lane 28, strain 21343; lane 29, strain 19535. (B) Primer KpnR. Lane 1, strain 20047; lane 2, strain VS461; lane 3, strain VS286; lane 4, strain VS468; lane 5, strain PBr; lane 6, strain PGau; lane 7, strain BO23; lane 8, strain TN; lane 9, strain SON188; lane 10, strain SON328; lane 11, strain CA5; lane 12, strain CA6; lane 13, strain DN127; lane 14, strain 21343; lane 15, strain 19535; lane 16, strain 26816.

various assumptions allowed us to reasonably assess some of the general features of a bacterial population.

Genetic distance estimates from fingerprinting data. Because AP-PCR randomly samples sequence polymorphisms distributed throughout the genome, AP-PCR fingerprints may be very accurate indicators of genetic distances. The matrix in Fig. 2 can be transformed into a pairwise distance matrix. The accompanying paper by Baranton et al. (5) gives pairwise measurements of levels of DNA homology between many of the strains included in this study. We compared these measurements of DNA homology levels with estimates of genetic distances determined by the AP-PCR. The result of this comparison is shown in Fig. 3. Thus, if the AP-PCR is appropriately calibrated, it can be used to measure genetic distances indirectly.

There are a number of different methods for measuring DNA homology by hybridization. Most of these methods are quite technically demanding and must be well controlled. On the other hand, AP-PCR is internally controlled and very simple. The reproducibility of AP-PCR fingerprints within a single experiment is excellent. The only factor that is likely to lead to sample-to-sample variability is template quality, which can be easily standardized. New taxa can be added to phylogenetic distance trees generated by using AP-PCR data more easily than to trees generated by using DNA-DNA hybridization data because AP-PCR data take the form of discrete characters. The results obtained with the AP-PCR method also compare favorably with the results obtained by multilocus enzyme electrophoresis because the AP-PCR protocol is simple and the number of polymorphisms that can be scored is virtually unlimited. Thus, the AP-PCR method for estimating genetic distances may have some advantages over other methods.

Phylogenetic analysis in which genetic distance was used. We used the Kitsch+ genetic distance algorithm in the PHYLIP phylogenetic analysis package to construct trees from AP-PCR pairwise distance measurements. This algorithm estimates phylogeny from distance matrix data by minimizing the differences between observed and expected pairwise distances, assuming that an evolutionary clock pertains. Ten replications with different addition sequences of the taxa were performed, and 20 taxa were analyzed at a 


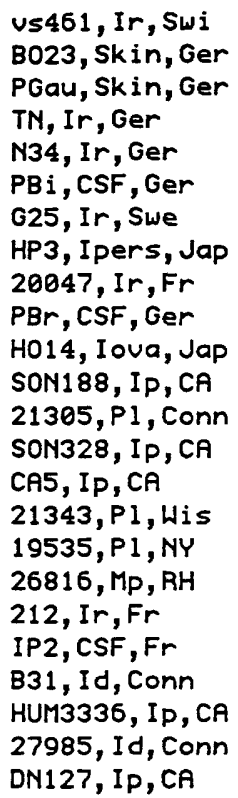

$010100000000001010000010100000000000000100001 ? 00000000$ $0101010000000000100000101000000000000001 ? 0001000110000$ $01010 ? 0000 ? 0000010000010100000000000000100001 ? 00010000$ $010010 ? 000000000101001000 ? 0000000000001010010011100000$ 010010100000000010100100010000000000001010010001100000 010110100000000010100100010000000000001010010001100000 $0101101000000000001001000 ? 0000000000001010010001100000$ $0001101000000000101001000 ? 0000000000001000010001100000$ 010110100000000010000100010000000000001000010011100000 010110100000000010100100000000000000001010010001100000 $0 ? 000 ? 001110000001000000000011000000011000010000001100$ $1110010100000001000000000001000000001000 ? 0100100000000$ $1 ? 1$ ? $01010000000100000000001100000010 ? 000 ? 1100000000000$ $11100 ? 010001000100 ? 0000000010000001 ? 000001100100000000$ 111001010000000100001000000100000011000001100100000000 101001010000000100000000000100000000100000100000000000 101001010000000100001000000100000000100001100100000000 101001010000000100001000000100000001000001100100000000 $111 ? 01010000000100010001000000000001000000100100 ? 00000$ $101 ? 01010000000100001000000000000001000001100100000000$ $101 ? 01 ? 10000000100001000000100000001000000100100000000$ $101 ? 01010000000100001000000000000011000001100100000000$ $101 ? 01010000000100001000000100000011000001100100000000$ $00000 ? 000000111000000000001000111100000010 ? 00000100011$

FIG. 2. Data matrix of AP-PCR polymorphisms. Polymorphisms shown in Fig. 1 and identified in three other experiments (data not shown) were scored as 1 (present), 0 (absent), or? (unknown). Strains T25, LAKE339, and HUM7814 were fingerprinted with only two primers (data not shown), and their fingerprint patterns were consistent with the species assignments in Table 1.

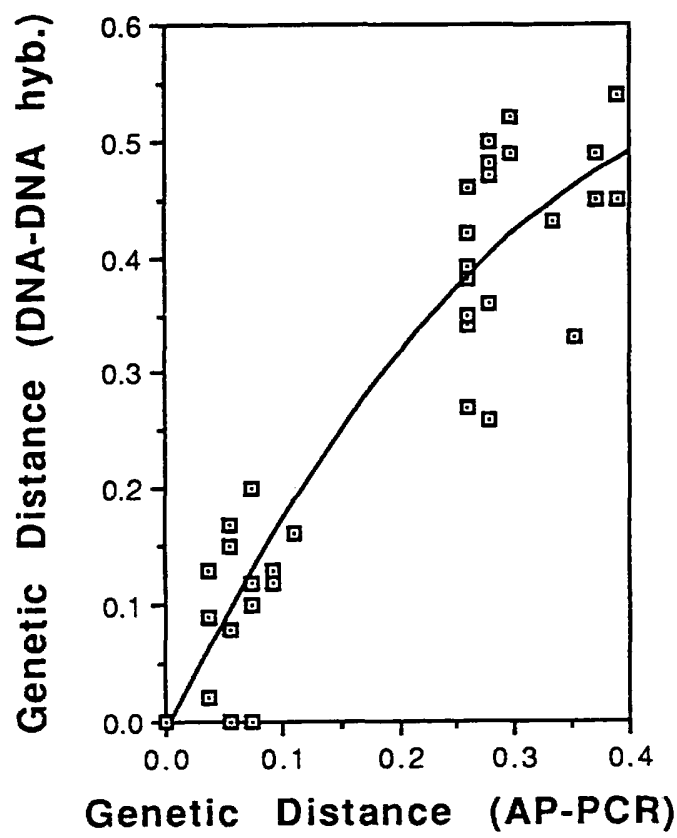

FIG. 3. Genetic distances as determined by DNA hybridization and by the AP-PCR. Levels of DNA homology were determined by Baranton et al. (5) and were converted to genetic distances. The genetic distance as estimated by the AP-PCR was calculated by dividing the number of differences between two taxa by the total number of characters, with question marks weighted as 0.5 . We do not know the functional form of the relationship between the two types of measurements, so the curve drawn on the graph is the best-fit (as determined by the least squares method) second-order polynomial and is only a rough approximation. time. All 10 trees were extremely similar to the tree shown in Fig. 4. In four of the trees the positions of strains IP2 and B31 were swapped, and in one of the trees the positions of strains $\mathrm{PBr}$ and $\mathrm{PBi}$ were swapped. In this analysis and in the parsimony analysis discussed below, strains VS286, VS468, and CA6 were omitted because they shared all of their informative characters with at least one other taxon. Four taxa (strains SON188, SON328, 19535, and 26816) were closely related to other taxa and were omitted for computational convenience. When these four taxa were included in the analyses in which either Kitch + or maximum parsimony was used, they were identified as members of group I and did not influence the overall structure of the phylogenetic trees.

The average pairwise genetic distances determined by the AP-PCR between members within each group defined in Fig. 4 were $0.050(\sigma=0.050)$ between group I isolates, 0.045 ( $\sigma$ $=0.019$ ) between group II isolates, and 0.043 between group III isolates. The average species-to-species genetic distances were $0.307(\sigma=0.026)$ between groups I and III, $0.387(\sigma=$ $0.032)$ between groups I and II, and $0.268(\sigma=0.014)$ between groups II and III. In another experiment (data not shown), eight North American isolates and one European isolate of $B$. burgdorferi were compared with Borrelia anserina by using this fingerprinting method. A total of 20 characters were scored, and the genetic distances were determined. The North American isolates were very similar to one another, while the European isolate and $B$. anserina differed markedly from each other and from the isolates obtained from North America.

We studied two Borrelia strains (strains DN127 and HO14) that were quite divergent from most members of the three main species. The smallest pairwise distance between strain DN127 and any other strain was 0.315 (compared with strain 21305) as measured by the AP-PCR, while the smallest pairwise distance between strain HO14 and any other strain as measured by the AP-PCR was 0.315 (compared with strains PGau, TN, G25, and HP3). These distances were large enough to hypothesize that strains DN127 and HO14 


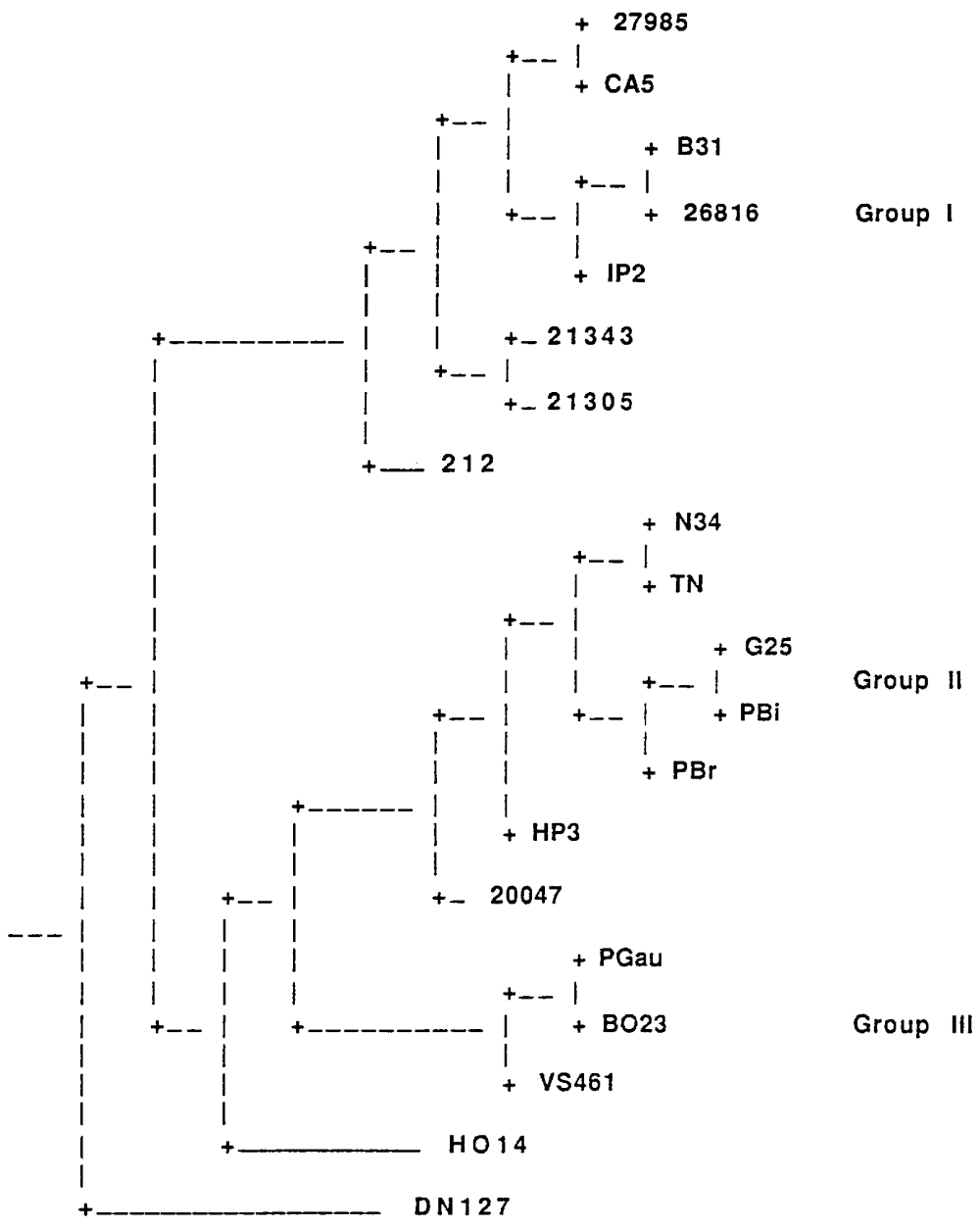

FIG. 4. Phylogenetic tree based on genetic distances. A phylogenetic tree for 20 strains representing the three species was determined by using the Kitsch + genetic distance method (14) and the PHYLIP phylogenetic package. Our version of this program could analyze a maximum of 20 taxa; 1 of 10 essentially identical trees generated from 10 different random addition sequences is shown. The sum of squares for this tree is 9.6 , and the average standard deviation is $15.9 \%$. The lengths of the branches do not strictly correspond to genetic distances.

represent distinct phyletic groups. However, strains DN127 and HO14 shared a number of AP-PCR fingerprint characters with all of the other strains used in the experiments. This indicates that these two strains are related to the other Borrelia strains and could serve as an outgroup in parsimony analysis. Confident assignment of these strains will require the isolation of additional related strains and comparison with other known species in the genus.

Phylogenetic analysis in which parsimony was used. In principle, parsimony analysis uses more information from the scoring matrix than genetic distance analysis does. However, phylogenetic analysis in which parsimony is used generally makes several assumptions concerning the nature of proper characters. Some investigators caution against using restriction fragment length data as phylogenetic characters, in part because the forward and reverse rates of change between the two character states $(0$ and 1$)$ are not equal. There are many more ways to lose an existing site than there are to regain the site once it has been lost. The same argument applies to polymorphisms generated by the AP-PCR.

AP-PCR data can be analyzed under a variety of conditions that assume either equal or unequal rates. At the one extreme, forward and reverse rates are assumed to be equal.
At the other extreme, parallel gains of the derived state (state 1) are forbidden. This condition of irreversibility corresponds to the Dollo assumption (26). Inevitably, a few characters are misscored because of the coincident migration of dissimilar AP-PCR products. Under the Dollo assumption these errors in scoring can sometimes result in severely distorted trees. In preliminary experiments, however, we found that a parsimony analysis of Streptococcus pyogenes in which we used AP-PCR fingerprint data allowed us to correctly classify different strains according to their surface M-protein types (29b). Thus, while care must be exercised in interpreting cladograms that are generated by applying maximum parsimony algorithms to this kind of data, it is clear that accurate phylogenetic comparisons can be made.

We analyzed the AP-PCR data for $B$. burgdorferi by performing a maximum parsimony analysis in which we used a variety of starting assumptions regarding character weights. Equal weighting, intermediate weighting (16), and Dollo weighting all resulted in the discrimination of the same three main phyletic groups that were distinguished in the genetic distance analysis performed by using the Kitch+ algorithm. For instance, Fig. 5 shows a $50 \%$ majority rule tree obtained from 31 trees generated by the branch-and- 


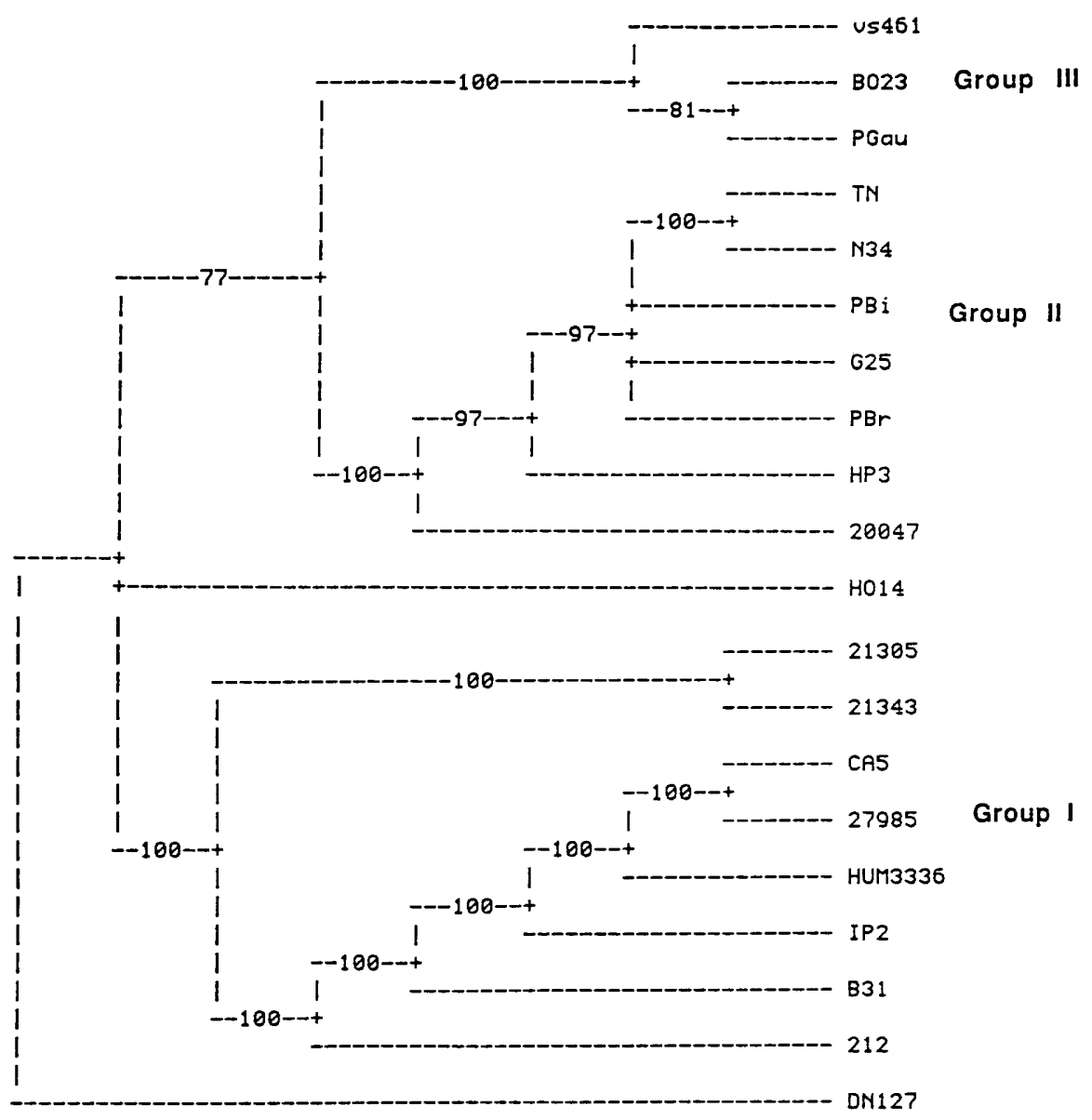

FIG. 5. Phylogenetic tree as estimated by parsimony analysis. A phylogenetic tree was determined by using parsimony analysis for the same 20 strains that were used to construct the tree shown in Fig. 4 (except that strain 26816 was replaced by strain HUM3336); these strains represented the three Borrelia species. This tree was based on an analysis of 34 informative characters and was solved by the branch-and-bound method contained within the PAUP (phylogenetic analysis using parsimony) phylogenetic inference package. The starting assumptions which we used are described in the text. The number at each branch point is the percentage of all of the shortest trees that had the branch.

bound search option in the phylogenetic inference package PAUP (26), using the ACCTRANS (accelerated transformation) option. This search algorithm identifies all of the shortest trees. Characters were uniformly weighted, and no penalty was assessed for parallel gains. The TBR (tree bisection-reconnection) algorithm was in effect, and strain DN127 was used as an outgroup. This analysis distinguished the same three main phyletic groups that were determined by applying the Kitch+ algorithm.

Some intraspecific structure was revealed by these analyses, but at the present time we have no independent criteria with which to judge the reliability of these structures. In addition, we do not know whether horizontal transfer of DNA occurs in the genus Borrelia. Such transfer would result in homoplasies in parsimony analysis, and the genetic distance tree would reflect only the principal components of the relationships between strains. Also, we know that certain plasmids can be lost in the genus Borrelia during in vitro culturing. While this probably represents only a small fraction of the total DNA complexity and thus a small fraction of the AP-PCR products, a differential loss between strains would lead to a slight increase in the apparent distance between strains.

\section{DISCUSSION}

The relationships among a set of Borrelia strains were determined by using genomic fingerprinting by AP-PCR without prior knowledge of the relatedness of the strains as determined by other methods. We identified groups of strains that subsequently proved to be the same groups that were determined by multilocus enzyme electrophoresis, DNA-DNA hybridization, and restriction fragment length polymorphism analysis by Baranton et al. (5) and Boerlin et al. (10). Strains generally regarded as members of $B$. burgdorferi fall into more than one phyletic group, and the groups diverge from each other in apparent DNA homology near the level of distinct species.

Each of the three phyletic groups which we delineated included isolates obtained from human infections, although the question of whether most or only a few of the strains isolated from nonhuman hosts can actually infect humans remains. Differences among the three phyletic groups may allow new correlations with differences in clinical symptomatology. Indeed, erythema chronicum migrans is a common symptom in North America, but lymphocytoma and acro- 
dermatitis, while admittedly uncommon symptoms in Europe, are virtually unknown in North America (27).

It is not yet clear why group II and III strains do not appear in the North American population. It is possible that these organisms cannot efficiently use Lxodes dammini as a vector or that the mammalian host population is restrictive. Considering the broad host range of these spirochetes, we think that the latter possibility is unlikely (4). One of the European group I strains used in this study was isolated from Lxodes ricinus. Therefore, it is possible that only members of group I are able to use both vectors. We are not aware of any studies that have tested this possibility.

One possibility is that the disease was recently introduced into North America from Europe since Lyme disease was not observed in North America for 60 years after its discovery in Europe. However, the diversity within group I strains probably excludes the hypothesis that there was a single recent European progenitor of the North American strains. Rather, if it is true that $B$. burgdorferi migrated from Europe to North America, either many group I strains must have migrated or the migration event must have happened long enough ago for the observed genetic diversity to have accumulated. Alternatively, the new appearance of the disease may have resulted from the de novo introduction of a virulence factor (e.g., a plasmid) into relatively benign strains that preexisted in North America. A more detailed phylogeny that includes more isolates belonging to group I from Europe, together with the North American strains, may answer these questions. If the migration of the species was recent, then the genetic diversity of the ancestral population was probably greater than the genetic diversity of the newly founded population.

The AP-PCR is a simple tool for estimating relatedness among species of bacteria that are closely related and among divergent strains within species. Using this method, we were able to categorize strains of $B$. burgdorferi into three related groups of potential species, in complete accordance with data obtained from multilocus enzyme electrophoresis, DNA-DNA hybridization, and rRNA gene restriction patterns $(5,10)$. At this level, the distinctions revealed by the AP-PCR are clear. The ability of the AP-PCR to resolve phylogenetic relationships between more closely related strains will require further study.

\section{ACKNOWLEDGMENTS}

We gratefully acknowledge Dave Ralph for suggesting this study. We thank R. Ackerman, J. F. Anderson, B. Bancillon, M. Janda, C. Kodner, E. J. Korenberg, R. Lane, T. Masuzawa, V. Preac-Mursic, A. Vogt, O. Peter, and B. Wilske for supplying strains. We thank Rita Wong for technical assistance.

This work was not funded by any government agency.

\section{REFERENCES}

1. Adam, T., G. S. Gassmann, C. Rasiah, and U. B. Gobel. 1991. Phenotypic and genotypic analysis of Borrelia burgdorferi isolates from various sources. Infect. Immun. 59:2579-2585.

2. Afzelius, A. 1910. Verhandlungen der Dermatologischen Gesellschaft zu Stockholm on October 28, 1909. Acta Dermatol. Syphilol. 101:404.

3. Anderson, J. F. 1989. Ecology of Lyme disease. Conn. Med. 53:343-346.

4. Anderson, J. F. 1989. Epizootiology of Borrelia in Lxodes tick vectors and reservoir hosts. Rev. Infect. Dis. 2(Suppl. 6): S1451-S1459.

5. Baranton, G., D. Postic, I. Saint Girons, P. Boerlin, J.-C. Piffaretti, M. Assous, and P. A. D. Grimont. 1992. Delineation of Borrelia burgdorferi sensu stricto, Borrelia garinii sp. nov., and group VS461 associated with Lyme borreliosis. Int. J. Syst. Bacteriol. 42:378-383.

6. Barbour, A. G. 1988. Plasmid analysis of B. burgdorferi, the Lyme disease agent. J. Clin. Microbiol. 26:475-478.

7. Barbour, A. G., W. Burgdorfer, S. E. Hayes, O. Peter, and A. Aeschlimann. 1983. Isolation of a cultivable spirochete from Lxodes ricinus ticks of Switzerland. Curr. Microbiol. 8:123-126.

8. Barbour, A. G., R. A. Heiland, and T. R. Howe. 1985. Heterogeneity of major proteins in Lyme disease borreliae: a molecular analysis of North American and European isolates. J. Infect. Dis. 152:478-484.

9. Bissett, M. L., and W. Hill. 1987. Characterization of Borrelia burgdorferi strains isolated from Ixodes pacificus ticks in California. J. Clin. Microbiol. 25:2296-2301.

10. Boerlin, P., O. Peter, A.-G. Bretz, D. Postic, G. Baranton, and J.-C. Piffaretti. Submitted for publication.

11. Brenner, D. J., A. C. McWhorter, J. K. Leete-Knudson, and A. G. Steigerwalt. 1982. Escherichia vulneris: a new species of Enterobacteriaceae associated with human wounds. J. Clin. Microbiol. 15:1133-1140.

12. Burgdorfer, W., A. G. Barbour, S. F. Hayes, J. L. Benach, E. Grunwaldt, and J. P. Davis. 1982. Lyme disease-a tick-borne spirochetosis? Science 216:1317-1319.

13. Felsenstein J. 1990. PHYLIP manual, version 3.3. University Herbarium, University of California, Berkeley.

14. Fitch, W. M., and E. Margoliash. 1967. Construction of phylogenetic trees. Science 155:279-284.

15. Johnson, R. C., G. Schmid, F. W. Hyde, A. G. Steigerwalt, and D. J. Brenner. 1984. Borrelia burgdorferi: etiologic agent of Lyme disease. Int. J. Syst. Bacteriol. 34:496-497.

16. Lawrence, J. G., D. E. Dykhuizen, R. F. DuBose, and D. Hartl. 1989. Phylogenetic analysis using insertion sequence fingerprinting in Escherichia coli. Mol. Biol. Evol. 6:1-14.

17. LeFebvre, R. B., G. C. Perng, and R. C. Johnson. 1989. Characterization of Borrelia burgdorferi isolated by restriction endonuclease analysis and DNA hybridization. J. Clin. Microbiol. 27:636-639.

18. Persing, D. H., S. R. Telford III, P. N. Rys, D. E. Dodge, T. J. White, S. E. Malawista, and A. Speilman. 1990. Detection of Borrelia burgdorferi DNA in museum specimens of Ixodes dammini ticks. Science 249:1420-1423.

19. Postic, D., C. Edlinger, C. Richaud, F. Grimont, Y. Dufresne, P. Perolat, G. Baranton, and P. A. D. Grimont. 1990. Two genomic species in Borrelia burgdorferi. Res. Microbiol. 141:465-475.

20. Rosa, P. A., D. Hogan, and T. G. Schwan. 1991. Polymerase chain reaction analyses identify two distinct classes of Borrelia burgdorferi. J. Clin. Microbiol. 29:524-532.

21. Schwan, T. G., W. Burgdorfer, and C. F. Garon. 1988. Changes in infectivity and plasmid profile of the Lyme disease spirochete, Borrelia burgdorferi, as a result of in vitro cultivation. Infect. Immun. 56:1831-1836.

22. Scrimenti, R. J. 1970. Erythema chronicum migrans. Arch. Dermatol. 102:104-105.

23. Simpson, W. J., C. F. Garon, and T. G. Schwan. 1990. Analysis of supercoiled circular plasmids in infectious and non-infectious Borrelia burgdorferi. Microb. Pathog. 8:109-118.

24. Steere, A. C., S. E. Malawista, J. A. Hardin, S. Ruddy, P. W. Askenase, and W. A. Andiman. 1977. Erythema chronicum migrans and Lyme arthritis-the enlarging clinical spectrum. Ann. Intern. Med. 86:685-698.

25. Stohlammar-Carlemalm, M., E. Jenny, L. Gern, A. A. Aeschlimann, and J. Meyer. 1990. Plasmid analysis and restriction fragment length polymorphisms of chromosomal DNA allow a distinction between Borrelia burgdorferi strains. Zentralbl. Bakteriol. Parasitenkd. Infektionskr. Hyg. Abt. 1 Orig. 274:28-39.

26. Swofford, D. L. 1991. PAUP: phylogenetic analysis using parsimony, version 3.0. Illinois Natural History Survey, Champaign.

27. Weber, K., G. Schierz, B. Wilske, et al. 1984. European erythema migrans diseases and related disorders. Yale J. Biol. Med. 57:463-471.

28. Welsh, J., R. J. Honeycutt, M. McClelland, and B. W. S. Sobral. 1991. Parentage determination in maize hybrids using arbitrarily primed PCR. Theor. Appl. Genet. 82:473-476. 
29. Welsh, J., and M. McClelland. 1990. Fingerprinting genomes using PCR with arbitrary primers. Nucleic Acids Res. 18:72137219.

29a.Welsh, J., and M. McClelland. 1991. Genomic fingerprinting using arbitrarily primed PCR and a matrix of pairwise combinations of primers. Nucleic Acids Res. 19:5275-5279.

29b.Welsh, J., and M. McClelland. Unpublished data.

30. Welsh, J., C. Peterson, and M. McClelland. 1991. Polymorphisms generated by arbitrarily primed PCR in the mouse: application to strain identification and genetic mapping. Nucleic
Acids Res. 19:303-306.

31. Williams, J. G. K., A. R. Kubelik, K. J. Livak, J. A. Rafalski, and S. V. Tingey. 1990. DNA polymorphisms amplified by arbitrary primers are useful as genetic markers. Nucleic Acids Res. 18:6531-6535.

32. Wilske, B., V. Preac-Mursic, G. Schierz, R. Kuhbeck, A. G. Barbour, and M. Kramer. 1988. Antigenic variability of Borrelia burgdorferi. Ann. N.Y. Acad. Sci. 539:126-143.

33. Woese, C. R. 1987. Bacterial evolution. Microbiol. Rev. 51:221227. 